Supporting Information:

\title{
Comprehensive characterization of bovine milk lipids: Triglycerides
}

\author{
Zhiqian Liu $^{1 *}$, Cheng Li ${ }^{1,2}$, Jennie Pryce ${ }^{1,2}$ and Simone Rochfort ${ }^{1,2}$
}

${ }^{1}$ Agriculture Victoria Research, AgriBio, 5 Ring Road, Bundoora, Victoria 3083, Australia

${ }^{2}$ School of Applied Systems Biology, La Trobe University, Bundoora, Victoria 3083, Australia

*Corresponding author: Zhiqian.liu@agriculture.vic.gov.au

Tel: +61390327134 
Table S-2: Linearity and relative response of TAG standards

\begin{tabular}{lcc}
\hline TAG group & Linear regression & $\mathrm{R}^{2}$ \\
\hline TAG 24:0 & $\mathrm{Y}=3003169 \mathrm{x}$ & 0.9999 \\
TAG 30:0 & $\mathrm{Y}=3410415 \mathrm{x}$ & 1.0000 \\
TAG 36:0 & $\mathrm{Y}=3287638 \mathrm{x}$ & 0.9980 \\
TAG 42:0 & $\mathrm{Y}=2768783 \mathrm{x}$ & 0.9966 \\
TAG 45:0 & $\mathrm{Y}=2768937 \mathrm{x}$ & 0.9975 \\
TAG 48:0 & $\mathrm{Y}=2568391 \mathrm{x}$ & 0.9976 \\
TAG 54:0 & $\mathrm{Y}=2547987 \mathrm{x}$ & 0.9926 \\
TAG 54:3 & $\mathrm{Y}=2186591 \mathrm{x}$ & 0.9891 \\
TAG 60:0 & $\mathrm{Y}=2299453 \mathrm{x}$ & 0.9998
\end{tabular}

$\mathrm{Y}$ : peak area $\left(\times 10^{6}\right) ; \mathrm{x}$ : concentration $(\mathrm{mg} / \mathrm{mL})$.

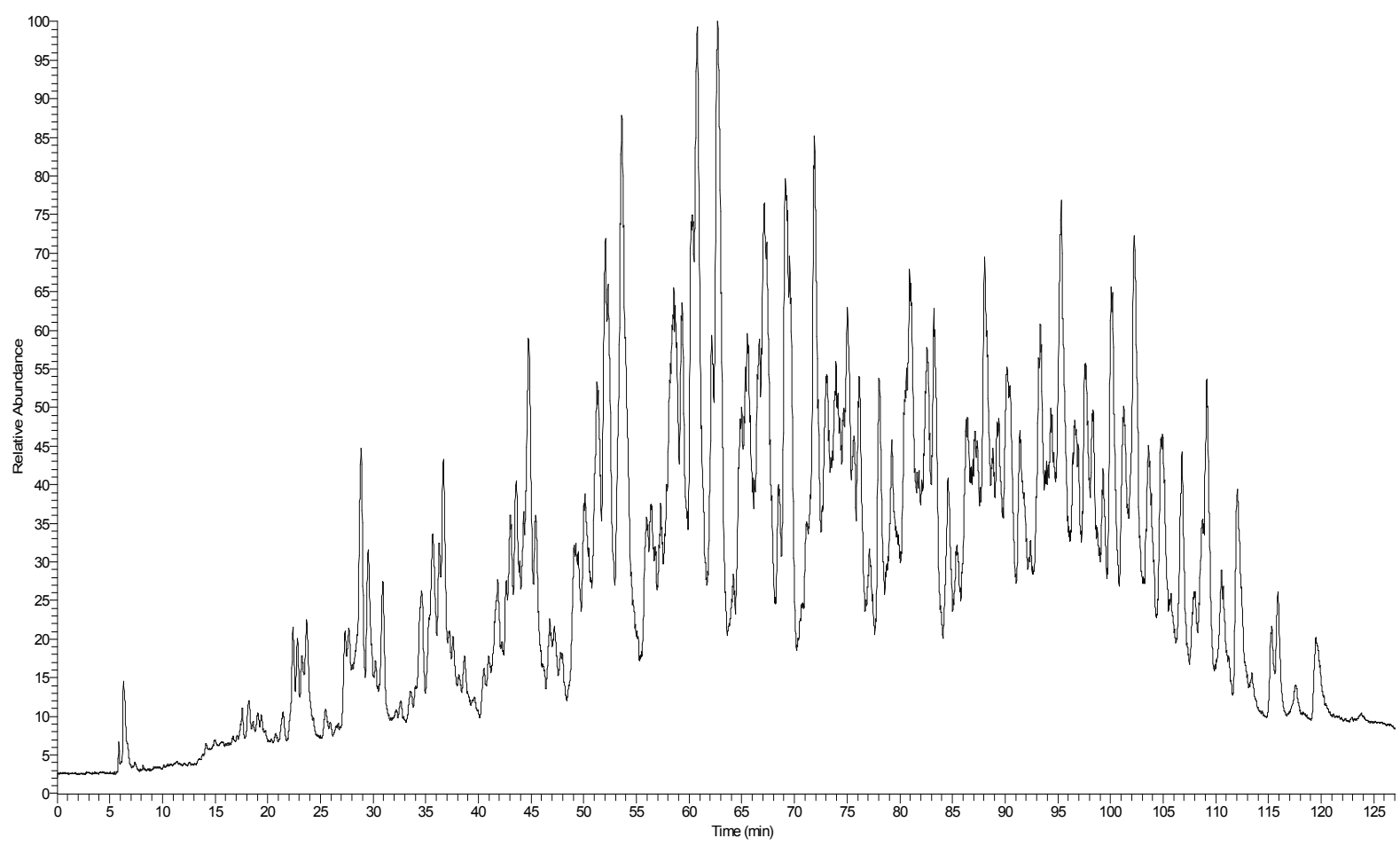

Figure S-1: Non-Aqueous-RP-LC-MS profile of bovine milk triglycerides (total ion chromatogram) 